\title{
Explaining faculty members' behavioral intention to use learning management systems
}

\author{
Konstantinos Lavidas $^{1}$ (D) ${\text { Vassilis } \text { Komis }^{2} \text { (D) }}$ Anthi Achriani $^{2}$
}

Received: 9 July 2021 / Revised: 26 October 2021 / Accepted: 22 December 2021 / Published online: 30 January 2022

(C) Beijing Normal University 2021

\begin{abstract}
Utilizing learning management system (LMS) in higher education and the factors could explain it is an emerging research field. Limited research has investigated factors influencing the adoption of LMS as a distinct system of e-learning as well as these studies mainly investigate the determinants of intention to use LMS from students and less from the point of view of the university instructors. This study investigates the factors that explain LMS acceptance from the faculty members. A version of the technology acceptance model including five external factors (perceived self-efficacy, subjective norm, image, technological complexity, and facilitating conditions) is proposed. The sample consists of 378 faculty members from 20 universities of Greece who declared to use LMS. A variance-based structural equation modeling was applied and ten out of thirteen hypotheses were confirmed. The total explained variance of behavioral intention to use LMS is estimated at $73 \%$. Attitudes toward use, perceived usefulness, perceived easy of use, technological complexity, perceived self-efficacy, and subjective norm are the main determinants of faculty members' behavioral intention to use LMS. Implications for training, educational policy, as well as the design and/or use of educational information systems are discussed.
\end{abstract}

Konstantinos Lavidas

lavidas@upatras.gr

Vassilis Komis

komis@upatras.gr

Anthi Achriani

anthi.achriani@gmail.com

1 Hellenic Open University \& University of Patras (Department of Educational Sciences and Early Childhood Education), University of Patras, 26500 Rio Achaia, Patras, Greece

2 Department of Educational Sciences and Early Childhood Education, University of Patras, 26500 Rio Achaia, Patras, Greece 
Keywords LMS $\cdot$ Moodle $\cdot$ eClass $\cdot$ Higher education E-learning $\cdot$ TAM $\cdot$ Greek faculty members

\section{Introduction}

E-learning is growing in popularity around the world, as it mitigates the time and space constraints associated with the traditional form of education (Panigrahi et al., 2018). Learning management system (LMS), massive open online courses, and other cloud-based classroom management systems are some of the several platforms which can be utilized for e-learning. LMS is a powerful online information system (IS) that facilitates learning and teaching practices and constitutes a widespread technology that is being used in higher education (Al-Nuaimi \& Al-Emran, 2021; Chaw \& Tang, 2018; Dahlstrom, Brooks \& Bischel 2014). LMS is one of the key web-based innovations to enhance e-learning programs (Cigdem \& Topcu, 2015). LMS focuses on online learning delivery both asynchronous and synchronous based and provides affordances for organizing digital educational material, instant messaging, posting, assignments, tracking learners' progress, blog services, etc. (Dahlstrom et al., 2014). There are many LMSs that are used in higher education, for example, a well-known LMS is the Moodle (modular object-oriented term developmental learning environment). This is an open source LMS and in 2021, it is used in 246 countries with 270 million users and 36 million courses (Moodle 2019). In Greek universities, two LMSs mainly are used: Moodle and eClass with the second to be provided with full technical official support. eClass is based on Claroline (https:// claroline.net/type/claroline), a collaborative e-learning LMS, and offers simple features for sharing educational material and assignments.

Considering the impact of LMS on education (Chaw \& Tang, 2018; Dahlstrom et al., 2014; Jaschik \& Lederman, 2014; Waheed et al., 2016), researchers have made significant effort to find out the factors which influence the users' intention to use LMS (Al-Nuaimi \& Al-Emran, 2021; Teo et al., 2019). According to a recent systematic research review although the last decade has seen a more intense investigation into the acceptance of LMS by the academic community, this research remains limited (Al-Nuaimi \& Al-Emran, 2021). Although there are studies about the adoption of e-learning systems in general by the academical community, limited research has investigated factors influencing the adoption of LMS as a distinct system of e-learning (Al-Nuaimi \& Al-Emran, 2021). Additionally, most of the research mainly examines the determinants of intention to use LMS from the students' perspective (e.g., Al-Nuaimi \& Al-Emran, 2021; Baleghi-Zadeh et al., 2017; Escobar-Rodriguez \& Monge-Lozano, 2012; Teo et al., 2019) and less form the faculty members' point of view of (Alharbi \& Drew, 2014; Altawalbeh \& Alassaf, 2018; Cigdem \& Topcu, 2015; Fathema, Shannon, \& Ross 2015; Wichadee, 2015).

In this study, we investigated the degree of acceptance of LMS by faculty members based on the technology acceptance model (TAM). This model is the most predominant theoretical model that has been used to study LMS acceptance and 
adoption in higher education institutions (Al-Nuaimi \& Al-Emran, 2021; Ziraba et al., 2020). Moreover, the TAM is considered as a robust model with a good fit and a good level of intention prediction in a variety of settings (Lavidas et al., 2019; Teo, 2010; Venkatesh \& Davis, 2000). Very often, TAM is used for investigating the intention to use websites, e.g., in e-commerce, in IS used by employees in financial corporations (Venkatesh, Morris, Davis, \& Davis 2003), (Venkatesh \& Davis, 2000), etc. Using the TAM, five external factors were tested for their impact mainly on perceived usefulness and ease of use in order to determine and predict the academics' intention to use LMS at higher education institutions. These personal and environmental factors affect perceived ease of use and usefulness and have been discussed in numerous studies (Panigrahi et al., 2018). In this study, the perceived selfefficacy (PSE) of faculty members along with PU and PEOU was used as a personal factor (Al-Busaidi \& Al-Shihi, 2010; Asiri et al., 2012; Cigdem \& Topcu, 2015; Fathema et al., 2015; Teo, 2009; Zheng et al., 2018) and the subjective norms (SN), image (I), facilitating conditions (FC), and the technological complexity (TC) as environmental factors (Al-Busaidi \& Al-Shihi, 2010; Cigdem \& Topcu, 2015; Fathema et al., 2015; Teo, 2010; Wang \& Wang, 2009; Zheng et al., 2018). For research, an integrated model of structural equations has been developed (Hair et al., 2017). Determining the factors affecting the behavioral intention to use LMS will feed the debate about the policies to enhance its usage by faculty members worldwide as well as in Greek universities.

Subsequently, a literature review on TAM for LMS use is presented, followed by research objectives and the formed hypotheses. Next, the measurements and the structural models used to test the hypotheses are presented. Lastly, research results, limitations, practical implications, and future potential of the research are discussed.

\section{Literature review}

The technology acceptance model (TAM) was introduced by Davis (1989); it is widely used to examine the acceptance of information systems (IS) and it is well known for its reliability and predictability. TAM is grounded on the theory of reasoned action (TRA), a theoretical basis that can predict and explain human behavior in many areas (Ajzen \& Fishbein, 1980). According to TAM, the two factors, perceived usefulness (PU) and the perceived ease of use (PEOU), are the predominant antecedents of technology adoption and they explain the intention (BI) to use through attitude (ATT) (Davis, 1989). PU is the extent to which a user believes that the IS improves its job performance. PEOU is the extent to which a user believes that working with the IS is easy to use. ATT of IS is the extent to which a user positively or negatively perceives the use of IS. BI is the degree of the user's intention to perform a certain behavior. PU and PEOU are regressed on a variety of external predictors. Besides the main factors (PU, PEOU, and ATT), these external factors also included in the TAM can determine the behavioral intention only indirectly, via the main factors. Research examining the intention of faculty to use LMS with TAM is an understudied research field worldwide. 
There are few studies based on the TAM investigating the adoption and use of LMS by the faculty members. Alharbi and Drew (2014) investigated three external factors that affect faculty members' LMS usage. Their sample consisted of 59 faculty members from Shaqra university in Saudi Arabia and their analysis revealed that all the three proposed external variables-lack of LMS availability, job relevance, and experience with LMS usage-were significantly correlated with PU and PEOU of the LMS. Furthermore, the correlations between the basic constructs of TAM confirmed the latter's adaptability. Similarly, Cigdem and Topcu, (2015), in Turkey with a sample of 115 instructors from Turkey, investigated their behavioral intention to use LMS at a postsecondary military vocational college level. They used the TAM framework including external factors such as self-efficacy, technological complexity, and subjective norm. According to their results, all the mentioned variables either directly or indirectly affect the overall behavioral intention to use LMS. With a sample of 560 faculty members from two public universities in the United States, Fathema, Shannon, \& Ross (2015) using TAM investigated three external factors that affect faculty members' LMS usage. Their findings revealed that the three proposed external factors: system quality, perceived self-efficacy, and facilitating conditions were significant predictors of attitude toward LMS. Additionally, Wichadee (2015) investigated the factors about the faculty members' attitudes toward LMS and the adoption of LMS in their courses. A survey with basic constructs of the TAM instrument was administered to 62 instructors of a private university in Thailand to examine their use of LMS. The findings revealed that the respondents of the study had a positive overall attitude toward LMS as well as PU and PEOU were the constructs with the highest positive correlations with the attitude toward LMS. Finally, more recently, with a sample of 320 instructors from Jordanian universities, Altawalbeh and Alassaf (2018) investigate their intention to adopt LMS by using TAM. According to their findings, the PU has a significant influence on behavioral intention BI, perceived usefulness PU, and PEOU have significant influence on ATT, but ATT has no significant impact on BI.

The previous studies include various specific external factors that cover part of the explanation of faculty members' behavioral intention to use LMS. This study attempts to give us a clearer and broader image including more of the previous factors. Moreover, very few empirical studies based on the TAM investigating the adoption and use of LMS by the faculty members as well as to the authors' knowledge, no previous similar attempt has been reported in Greece for the Greek faculty member population so far. Consequently, the present research has the following aims:

- Confirmation of the adaptability and validity of TAM regarding the Greek sample of the faculty members in order to determine their intention to use an LMS in their educational process.

- Exploring the influence of external factors regarding the intention of using LMS by the Greek faculty members. The external factors are perceived IS self-efficacy, subjective norms, image, technological complexity, and facilitating conditions. 


\section{Conceptual model}

The conceptual model includes the main factors of TAM (PU, PEOU, ATT, and BI), the external factors (perceived IS self-efficacy, subjective norms, image, technological complexity, and facilitating conditions), as well as the direct effects among these factors. Figure 1 presents the formulated hypotheses, that is, the direct effects among the factors, which are analytically discussed below. The two most critical beliefs that seem to influence acceptance of technology are perceived usefulness (PU) and perceived ease of use (PEOU) of the LMS (Alharbi \& Drew, 2014; Altawalbeh \& Alassaf, 2018; Cigdem \& Topcu, 2015; Granic \& Marangunic, 2019; Lavidas et al., 2019; Wichadee, 2015). TAM borrows the concept of behavioral intention (BI) and attitudes toward use (ATT) concerning the use of an IS from the Theory of Reasoned Action (Ajzen \& Fishbein, 1980). The hypotheses related to four original TAM constructs are as follows:

H1 PEOU presents a positive effect on PU of the LMS.

H2 PEOU presents a positive effect on ATT of the LMS.

H3 PU presents a positive effect on ATT of the LMS.

H4 PU presents a positive effect on BI to use the LMS.

H5 ATT presents a positive effect on BI to use the LMS.

Perceived self-efficacy (PSE) refers to a person's beliefs regarding his/her ability to perform certain functions that affect his or her life (Compeau \& Higgins, 1995;

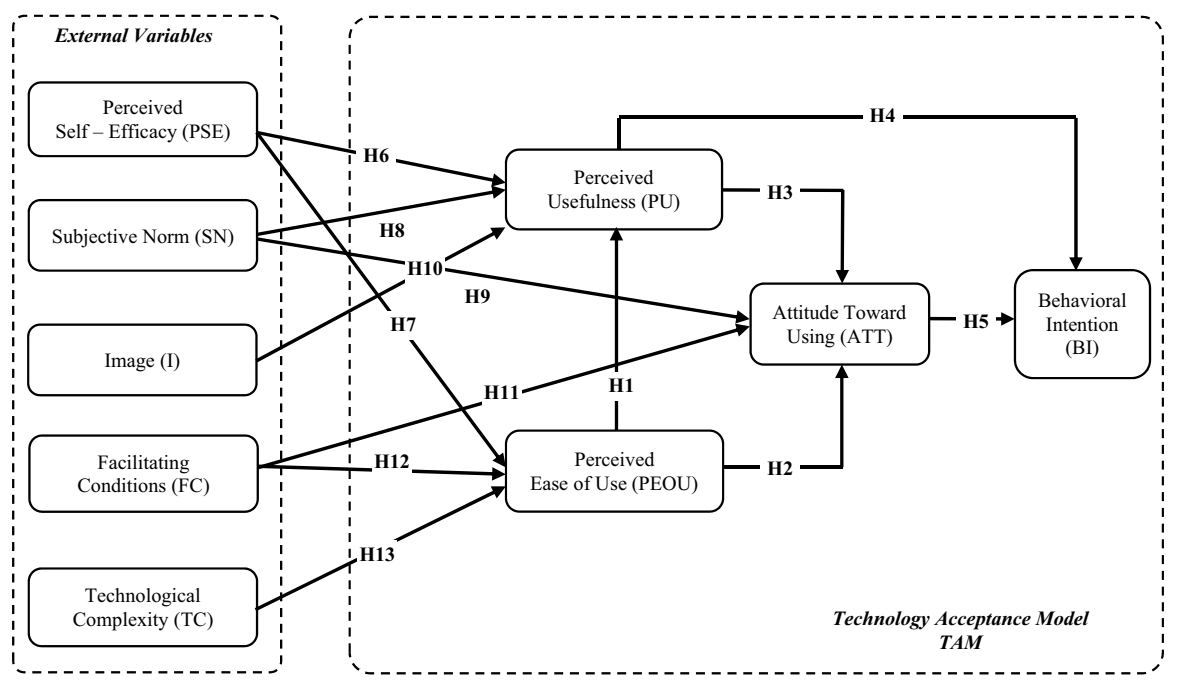

Fig. 1 The formulated research model 
Lavidas et al., 2019). In the context of this research, reference is made to technological self-efficacy, which is the subjective perception of the user about his/her ability to use the technological means for carrying out a task and, in particular, an LMS task. Perceived self-efficacy (PSE) is commonly found in the literature and shows how perceptions about performance abilities in similar environments can predict the intention of using the information system (IS) (Lavidas et al., 2019). PSE has an impact on the user's PU (Cigdem \& Topcu, 2015; Fathema et al., 2015; Zheng et al., 2018) and on the user's PEOU, as well (Cigdem \& Topcu, 2015; Fathema et al., 2015; Lavidas et al., 2019; Teo, 2009; Wang \& Wang, 2009). According to the literature, the assumptions formed are as follows:

H6 PSE presents a positive effect on PU.

\section{H7 PSE presents a positive effect on PEOU.}

Subjective norms (SN) consist of a person's perception of whether to perform a particular behavior or not according to the views of his/her social environment (Davis, 1989). More specifically, it refers to the beliefs, and consequently to the behaviors, that the individual performs taking into consideration what the sociocultural environment expects of him/her to do. Research has shown that the user's subjective norms $(\mathrm{SN})$ form the intention to use technology through their effect on the factor of PU and ATT (Cigdem \& Topcu, 2015; Lavidas et al., 2019; Venkatesh \& Davis, 2000; Wang \& Wang, 2009). Thus, the following assumptions are as follows:

\section{H8 SN presents a positive effect on PU.}

\section{H9 SN presents a positive effect on ATT of LMS.}

Image (I) is defined as the degree to which a person thinks that using an innovation will enhance his/her social profile within a social system (Venkatesh \& Davis, 2000). In other words, when the user is convinced that the use of technology in his/ her professional activities will give him/her prestige in the working environment, this seems to influence his/her perception that such a technology is useful (Lavidas et al., 2019; Venkatesh \& Davis, 2000). Thus, the resulting hypothesis is the following:

H10 Image positively affects the user's PU of the LMS.

Facilitating conditions (FC) are defined as the objective environmental factors that help to achieve a task and are accepted by a wide audience (Thompson Higgins \& Howell 1991). In the case of technology, FC consist of features \& functions of a particular IS, e.g., technical support in the form of instructions (Thompson et al., 1991). Numerous researches have been conducted about the system quality, with the results showing that the offered affordances and the facilitating factors of an IS influence a person's perception of the ease of use of such a system (Fathema et al., 
2015; Şahin et al., 2021; Teo, 2010; Zheng et al., 2018) and contribute to the formation of a positive attitude toward the use of the said system (Fathema et al., 2015; Lavidas et al., 2019; Teo, 2010). Thus, the hypotheses arising from the literature are as follows:

\section{H11 FC presents a positive effect on user's ATT .}

H12 FC presents a positive effect on the user's PEOU.

Technological complexity (TC) is the extent to which an innovation is perceived as being relatively difficult to understand and to use (Thompson et al., 1991). In the context of LMS, technological complexity (TC) is perceived as the inverse of ease of use (Cigdem \& Topcu, 2015; Lavidas et al., 2019; Wichadee, 2015), and consequently, it seems to reduce the PEOU of the system (Teo, 2009). Thus, the hypotheses arising from the literature are as follows:

H13: TC presents a negative effect on PEOU.

\section{Methodology}

\section{Research procedure and instruments}

Similarly, with previous research, the research methodology was based on a quantitative paradigm (Creswell, 2002). The research was conducted from March to April 2019 and the questionnaire was randomly administrated to 1500 out of almost 8000 existing faculty members in Greece, using their public email addresses. Initially, the faculty members were informed that the questionnaire is anonymous and that the information gathered will be utilized strictly for research purposes. Faculty members who used LMS were asked to consent to participate in the survey, according to the new general data protection regulation (GDPR), giving them the possibility when they decide to escape from the survey.

The questionnaire consisted of two sections. The first section included demographic information (gender, years of teaching, university, LMSs that are mainly used) and the second part was comprised of 26 items: "PU" 4 items, "PEOU" 4 items, "ATT" 4 items, "BI" 3 items, "PSE" 2 items, "SN" 2 items, "FC" 3 items, "TC" 2 items, and "I" 2 items. All the participants using a 7-point Likert-type scale " $1=$ strongly disagree to $7=$ strongly agree", answered all items. All items used in this study are adaptations of previous studies that were used in technology acceptance of information systems (IS), but not necessarily in LMS. Therefore, we utilized items for PEOU and PU from Davis (1989), items for ATT and BI from Fathema et al. (2015), items for PSE from Compeau and Higgins (1995), items for SN and image (I) from Thompson et al. (1991), and Venkatesh and Davis (2000), and items for TC (negative wording items) from Teo (2009). The final version of the research instrument (see Appendix) was based on the results of an interview with fifteen faculty members. According to the difficulties and ambiguities in interpreting the items 
that were declared by this sample, the wording in some items was revised. Finally, all the items of the second part were randomly distributed.

\section{Sample}

Table 1 presents the demographics of the 378 participants. These faculty members were from the most tertiary institutions in Greece, who declared that they mainly use eClass (72.5\%) and Moodle (27.5\%) at least once a week as tools for supporting remote teaching and learning.

\section{Method of analysis}

For the analysis, variance-based structural equation modeling (VB-SEM) was used, that is, partial least squares - structural equation modeling (PLS-SEM) analysis (Sanchez, 2013). This analysis is a contemporary multivariate method that is used for analyzing the relationships among multiple sets of variables (Hair et al., 2017). This analysis is flexible to sample size and normal distribution and is considered suitable for confirmatory analysis (Hair et al., 2017). The analysis was performed in an R (R Core Team, 2018) environment with the 'plspm' package (Sanchez, Trinchera, \& Russolillo 2017). The measurement model was initially evaluated, followed by an evaluation of the structural model (Hair et al., 2017).

\section{Results}

\section{Measurement model}

All the indicators in the measurement model present loadings larger than 0.7 (Table 2) without cross-loadings (Hair et al., 2017). The Cronbach's alpha and composite reliability (CR) criteria over 0.7 are considered as a high degree of internal reliability in all constructs (Hair et al., 2017). Also, the convergent validity for all factors is satisfactory since the average variance extracted (AVE) is over 0.5 (Fornell \& Larcher 1981; Hair et al., 2017).

As it is shown in Table 3, Fornell-Larcher (Fornell \& Larcher 1981) criterion revealed satisfactory discriminant validity since the square root of each construct's AVE (diagonals in parentheses) is greater than all the correlations between constructs.

\section{Structural model}

Path coefficients among constructs and the magnitude of explained variance in the endogenous construct (R-square) by its exogenous construct were determined to test the structural model (Hair et al., 2017). As it is shown in Table 4, 10 of the 13 hypotheses are supported, since the confidence intervals of the 


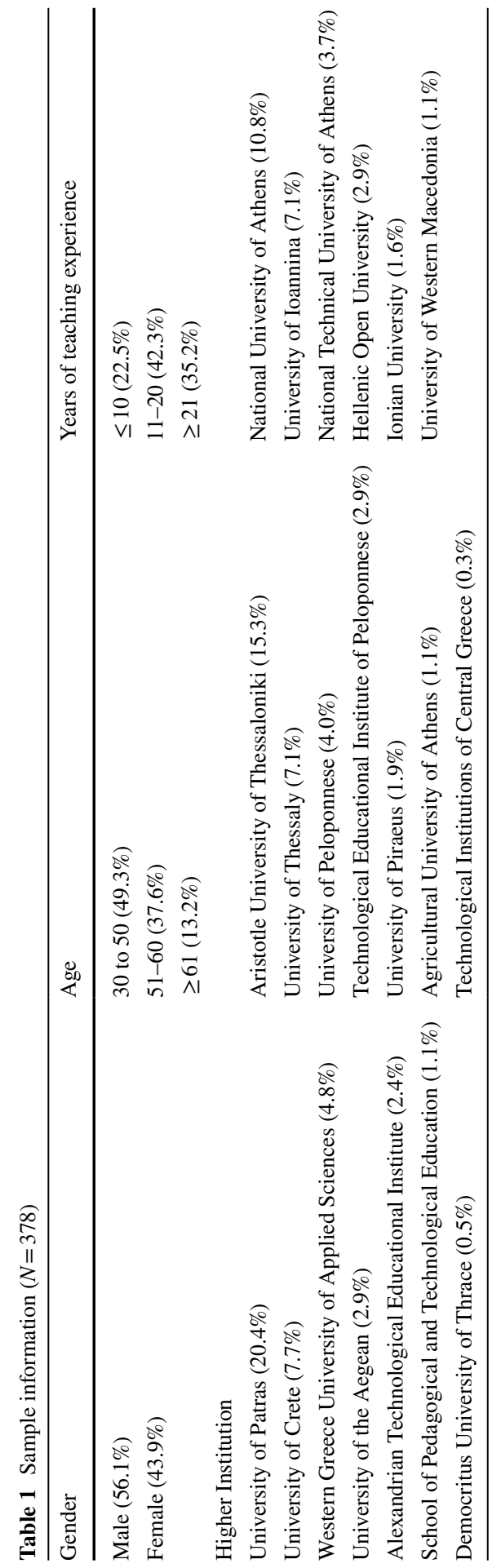


Table 2 Mean, standard deviations (SD), and reliability and validity indexes for each construct of the measurement model

\begin{tabular}{|c|c|c|c|c|c|}
\hline & Mean (SD) & Factor loadings & Cronbach's alpha & $\begin{array}{l}\text { Composite } \\
\text { reliability } \\
\text { (CR) }\end{array}$ & $\begin{array}{l}\text { Average variance } \\
\text { extracted (AVE) }\end{array}$ \\
\hline $\begin{array}{l}\text { Behavioral intention } \\
\text { to use }\end{array}$ & $6.38(.59)$ & & .815 & .890 & .730 \\
\hline BI1 & & .812 & & & \\
\hline BI2 & & .866 & & & \\
\hline $\mathrm{BI} 3$ & & .883 & & & \\
\hline $\begin{array}{l}\text { Attitude toward } \\
\text { using }\end{array}$ & $6.23(.64)$ & & .871 & .912 & .723 \\
\hline ATT1 & & .902 & & & \\
\hline ATT2 & & .814 & & & \\
\hline ATT3 & & .888 & & & \\
\hline ATT4 & & .791 & & & \\
\hline $\begin{array}{l}\text { Perceived ease of } \\
\text { use }\end{array}$ & $5.79(.87)$ & & .874 & .914 & .726 \\
\hline PEOU1 & & .844 & & & \\
\hline PEOU2 & & .823 & & & \\
\hline PEOU3 & & .852 & & & \\
\hline PEOU4 & & .890 & & & \\
\hline Perceived usefulness & $5.74(.86)$ & & .887 & .922 & .747 \\
\hline PU1 & & .919 & & & \\
\hline PU2 & & .824 & & & \\
\hline PU3 & & .894 & & & \\
\hline PU4 & & .816 & & & \\
\hline $\begin{array}{l}\text { Perceived self- } \\
\text { efficacy }\end{array}$ & $4.86(1.29)$ & & .715 & .875 & .777 \\
\hline PSE1 & & .899 & & & \\
\hline PSE2 & & .863 & & & \\
\hline Subjective norms & $4.80(1.07)$ & & .816 & .916 & .843 \\
\hline SN1 & & .935 & & & \\
\hline $\mathrm{SN} 2$ & & .901 & & & \\
\hline $\begin{array}{l}\text { Facilitating condi- } \\
\text { tions }\end{array}$ & $4.99(1.29)$ & & .843 & .907 & .765 \\
\hline FC1 & & .913 & & & \\
\hline $\mathrm{FC} 2$ & & .915 & & & \\
\hline FC3 & & .790 & & & \\
\hline Image & $4.04(1.31)$ & & .823 & .919 & .845 \\
\hline I1 & & .886 & & & \\
\hline $\mathrm{I} 2$ & & .951 & & & \\
\hline $\begin{array}{l}\text { Technological com- } \\
\text { plexity }\end{array}$ & $2.79(1.31)$ & & .765 & .895 & .809 \\
\hline TC1 & & .914 & & & \\
\hline TC2 & & .884 & & & \\
\hline
\end{tabular}


Table 3 Discriminant validity matrix (Fornell-Larcher criterion)

\begin{tabular}{|c|c|c|c|c|c|c|c|c|c|}
\hline Constructs & $\mathrm{BI}$ & ATT & PEOU & PU & PSE & SN & I & $\mathrm{FC}$ & $\mathrm{TC}$ \\
\hline $\mathrm{BI}$ & $(.854)$ & & & & & & & & \\
\hline ATT & $.843^{*}$ & $(.850)$ & & & & & & & \\
\hline PEOU & $.551 *$ & $.632 *$ & $(.852)$ & & & & & & \\
\hline PU & $.748 *$ & $.784 *$ & .568 & $(.864)$ & & & & & \\
\hline PSE & $.251 *$ & $.346^{*}$ & $.560 *$ & $.349^{*}$ & $(.881)$ & & & & \\
\hline SN & $.283^{*}$ & $.304 *$ & $.252^{*}$ & $.408 *$ & $.244^{*}$ & $(.918)$ & & & \\
\hline I & $.208 *$ & $.176^{*}$ & $.107 *$ & $.237 *$ & $.091 *$ & $.373^{*}$ & $(.919)$ & & \\
\hline $\mathrm{FC}$ & $.247 *$ & $.342 *$ & $.498^{*}$ & $.307 *$ & $.774 *$ & $.234^{*}$ & $.122 *$ & $(.875)$ & \\
\hline $\mathrm{TC}$ & $-.357 *$ & $-.379 *$ & $-.545^{*}$ & $-.326^{*}$ & $-.300^{*}$ & $-.108 *$ & .071 & $-.243^{*}$ & $(.899)$ \\
\hline
\end{tabular}

${ }^{*} p<.05$. Off-diagonal are correlations among constructs

Table 4 Structural model: Path significance and 95\% confidence interval test with bootstrapping (5000 samples)

\begin{tabular}{|c|c|c|c|c|c|c|}
\hline Нуро & esis & Direct Path & $95 \% \mathrm{CI}$ & $\mathrm{T}$-stat & p-value & Results \\
\hline $\mathrm{H} 1$ & $\mathrm{PEOU} \longrightarrow \mathrm{PU}$ & .493 & {$[.391, .590]$} & 8.330 & .000 & Supported $(*)$ \\
\hline $\mathrm{H} 2$ & PEOU $\longrightarrow$ ATT & .266 & {$[.181, .346]$} & 6.670 & .000 & Supported $(*)$ \\
\hline H3 & $\mathrm{PU} \longrightarrow \mathrm{ATT}$ & .638 & {$[.571, .703]$} & 16.600 & .000 & Supported $(*)$ \\
\hline $\mathrm{H} 4$ & $\mathrm{PU} \longrightarrow \mathrm{BI}$ & .227 & {$[.131, .317]$} & 5.250 & .000 & Supported $(*)$ \\
\hline H5 & $\mathrm{ATT} \longrightarrow \mathrm{BI}$ & .665 & {$[.575, .756]$} & 15.400 & .000 & Supported $(*)$ \\
\hline H6 & $\mathrm{PSE} \longrightarrow \mathrm{PU}$ & .004 & {$[-.110, .113]$} & .079 & .937 & Not Supported \\
\hline $\mathrm{H} 7$ & $\mathrm{PSE} \longrightarrow>\mathrm{PEOU}$ & .319 & {$[.182, .469]$} & 5.320 & .000 & Supported (*) \\
\hline $\mathrm{H} 8$ & $\mathrm{SN} \longrightarrow \mathrm{PU}$ & .249 & {$[.154, .337]$} & 5.550 & .000 & Supported $(*)$ \\
\hline H9 & $\mathrm{SN} \longrightarrow \mathrm{ATT}$ & -.029 & {$[-.084, .029]$} & .866 & .387 & Not Supported \\
\hline H10 & $\mathrm{I} \longrightarrow \mathrm{PU}$ & .091 & {$[.009, .177]$} & 2.270 & .024 & Supported $(*)$ \\
\hline H11 & $\mathrm{FC} \longrightarrow \mathrm{ATT}$ & .021 & {$[-.052, .097]$} & .595 & .552 & Not Supported \\
\hline H12 & $\mathrm{FC} \longrightarrow \mathrm{PEOU}$ & .151 & {$[.009, .282]$} & 2.560 & .011 & Supported $(*)$ \\
\hline H13 & $\mathrm{TC} \longrightarrow \mathrm{PEOU}$ & -.413 & {$[-.490,-.333]$} & -10.500 & .000 & Supported $(*)$ \\
\hline
\end{tabular}

${ }^{*} p<.05$

direct paths do not include zero. According to Cohen (1977), most path coefficients range from "moderate" to "high."

In Table 5, the indirect, direct, and total effects for each exogenous construct on the corresponding endogenous constructs of TAM, as well as the total explained variance for each endogenous construct, are presented. For the BI $\left(\mathrm{R}^{2}=73.04 \%\right)$ and ATT $\left(\mathrm{R}^{2}=66,67 \%\right)$, the total explained variance is considered "high" while for the other constructs, this explained variance is considered moderate (Hair et al., 2017; Sanchez, 2013). 
Table 5 Effects on endogenous constructs and analysis of explained variance

\begin{tabular}{|c|c|c|c|c|c|c|}
\hline Endogenous & Exogenous & Direct eff & Indirect eff & Total eff & Correlation & $\begin{array}{l}\text { Explained } \\
\text { variance } \\
\left(\mathrm{R}^{2}\right)\end{array}$ \\
\hline \multirow[t]{9}{*}{ BI } & & & & & & $73.04 \%$ \\
\hline & PU & .227 & .425 & .651 & .748 & $16.98 \%$ \\
\hline & ATT & .665 & - & .665 & .843 & $56.06 \%$ \\
\hline & PEOU & - & .498 & .498 & & \\
\hline & PSE & - & .161 & .161 & & \\
\hline & SN & - & .143 & .143 & & \\
\hline & I & - & .060 & .060 & & \\
\hline & $\mathrm{FC}$ & - & .089 & .089 & & \\
\hline & $\mathrm{TC}$ & - & -.206 & -.206 & & \\
\hline \multirow[t]{7}{*}{ PU } & & & & & & $40.44 \%$ \\
\hline & PEOU & .493 & - & .493 & .568 & $28.00 \%$ \\
\hline & PSE & .004 & .157 & .161 & .349 & $.14 \%$ \\
\hline & SN & .249 & - & .249 & .408 & $10.15 \%$ \\
\hline & I & .091 & - & .091 & .237 & $2.15 \%$ \\
\hline & $\mathrm{TC}$ & -- & -.204 & -.204 & & \\
\hline & $\mathrm{FC}$ & - & -.075 & -.075 & & \\
\hline \multirow[t]{8}{*}{ ATT } & & & & & & $66.67 \%$ \\
\hline & PU & .638 & - & .638 & .784 & $50.02 \%$ \\
\hline & PEOU & .266 & .315 & .581 & .632 & $16.81 \%$ \\
\hline & SN & -.029 & .159 & .130 & .304 & $.88 \%$ \\
\hline & $\mathrm{FC}$ & .021 & .088 & .109 & .342 & $.72 \%$ \\
\hline & I & - & .058 & .058 & & \\
\hline & PSE & - & .187 & .187 & & \\
\hline & $\mathrm{TC}$ & - & -.240 & -.240 & & \\
\hline \multirow[t]{4}{*}{ PEOU } & & & & & & $47.88 \%$ \\
\hline & PSE & .319 & - & .319 & .560 & $17.86 \%$ \\
\hline & $\mathrm{FC}$ & .151 & - & .151 & .498 & $7.52 \%$ \\
\hline & $\mathrm{TC}$ & -.413 & - & -.413 & -.545 & $22.50 \%$ \\
\hline
\end{tabular}

\section{Discussion}

This research aimed to establish the applicability of TAM with faculty members in order to determine their intention to use an LMS in their educational process as well as to determine the external factors that explain this. Results seem to advocate that the TAM version is a good adaptation to the factors which determine the LMS use by faculty members. The results indicate that PU and ATT have a direct effect on BI, while PEOU, PSE, SN I, FC, and TC affect BI indirectly. In this study, the total explained variance of BI is high (73.04\%), which matches with findings from previous studies (Cigdem \&Topcu 2015; Fathema et al., 2015). Regarding the total effect on BI, the greatest comes from ATT. Findings support 
the existing literacy that wants PU and PEOU to be determined for BI to use an information system (IS) (Alharbi \& Drew, 2014; Altawalbeh \& Alassaf, 2018; Cigdem \& Topcu, 2015; Davis, 1989; Granic \& Marangunic, 2019; Lavidas et al., 2019; Wang \& Wang, 2009). PU has a greater total effect on BI than PEOU. Therefore, instructors that see their teaching effectiveness are enhanced with LMS, and they are more likely to have behavioral intention to utilize the LMS. The results converge with previous research (Alharbi \& Drew, 2014; Altawalbeh \& Alassaf, 2018; Cigdem \&Topcu, 2015; Wichadee, 2015) that the usefulness of the LMS is that of prevailing over ease of use for the end-user.

The PU, a determining factor in the acceptance of technology, is explained by $40.44 \%$ and this explained variance is the result of the influence of four exogenous factors (PEOU, SN, I, and PSE). The PEOU has the greatest total effect on PU by all other exogenous factors affecting it. This is in line with previous research (Alharbi \& Drew, 2014; Altawalbeh \& Alassaf, 2018; Cigdem \&Topcu 2015; Teo, 2009; Wang \& Wang, 2009), that is, when a user finds that an IS is easy to use, it automatically gives the impression that it is useful. The explained variance for ATT is $66.67 \%$ and it is formed by four exogenous determinants (PU, PEOU, FC, and SN). It seems that the user forms his attitude toward the IS taking the usefulness more into account than the ease of use (Lavidas et al., 2019; Teo et al., 2019). The variance of PEOU is explained by $47.88 \%$ by three exogenous determinants (PSE, FC, and TC).

PSE predicts instructors' BI to use LMS through PEOU; therefore, the higher the PSE of the faculty members, the higher their behavioral intention to use LMS. PSE seems to affect PEOU as it was expected. This impact of PSE is in line with previous studies (Cigdem \& Topcu, 2015; Fathema, Shannon, \& Ross 2015; Lavidas et al., 2019).

The effect of SN on BI is also in agreement with the studies of Venkatesh and Davis, (2000) and Cigdem and Topcu, (2015). SN shows a remarkable effect on BI through PU. When the direct social circle (work, friends, etc.) shows that the LMS is a desirable practice, the users usually adopt it. SN seems to have no statistically significant direct effect on ATT as it was initially hypothesized (hypothesis 9) but it has an interesting total effect $(\beta=0.13)$. The factor of image (I) in the working environment and its influence on PU of the LMS seem to be very low $(\beta=0.09)$, but statistically significant. Similarly, in Venkatesh and Davis' study (2000), the effect of the image on the PU of the system also appears to be low (0.19 to 0.21$)$.

TC also shows to affect teachers' BI to use LMS through PEOU. TC appears to be the factor that explains the biggest percentage of variance and shows a negative effect on PEOU, just as assumed. It is obvious that the more complex a system is, the more it moves the user away from the idea that it can be easily used (Cigdem \& Topcu, 2015).

FC also shows to affect teachers' BI to use LMS through PEOU. When the system is characterized by facilitating elements such as frequently asked questions and technical support service, the user perceives the LMS as easy to use. This impact of FC is in line with previous studies (Fathema, Shannon, \& Ross, 2015; Lavidas et al., 2019). 


\section{Implications and limitations}

The research results highlight important issues that need to be addressed to ensure the effective use of LMS by academics. It turned out that the technological complexity of the LMS affects negatively their perceived ease of use. Also, users seem to put a lot of weight on the facilitating conditions of the LMS. Therefore, it would be expedient that the competent bodies of the universities and the designers of LMS do focus their attention on the affordances, quality, and technical support services, especially for the existing offered LMS (Zheng et al., 2018). The user-friendly desktop, command menus, and clear options are issues that should not confuse the end-user. As reported in other relevant studies (Fathema et al., 2015) regular monitoring for feedback would be good for maintaining and improving these domains.

The findings showed that the perceived self-efficacy of academics in using the LMS influences their perception of ease of use. Academics and other personnel such as teaching assistants which contribute to the teaching process need to be trained on the technologies that facilitate the learning process to gain comfort and familiarity with their use (Parissi et al., 2019). Generally, a positive vibe should be created to promote LMS that improves the teaching and learning process so that the intention to use and accept LMS will be increased. A forum about the affordances and the limitations of LMS as well as various guidelines and suggestions could motivate the faculty members to use LMS and simultaneously to urge some of them to attend a training program. In this program, some well-designed practices of faculty members with the usage of LMSs that support more effective teaching and enhance the students' engagement could be presented. Therefore, trainee faculty members will be able to choose what meets the needs of their courses, considering the benefits to their student's learning and the organization of their teaching (Zheng et al., 2018).

This study has some limitations that could serve as avenues for further research. However, due to the use of cross-sectional data, we should be cautious about the inferences about causality (Creswell, 2002). Also, the fact that volunteers were asked to present their perceptions and intentions to use an IS is an issue that usually leads to response biases (Lavidas \& Gialamas, 2019) and maybe to the low response rate (in this research 25,2\%). However, although high response rates are preferred, low response rates do not necessarily lead to biased results in multivariate models (Rindfuss et al., 2015). Also, taking into account that other scholars consider the more recent UTAUT model (Venkatesh et al., 2003) more suitable than the TAM for computer usage among educators (Ling et al., 2011), research should be carried out to investigate the applicability of UTAUT with faculty members. Moreover, future studies, mainly longitudinal, could be carried out with representative samples to establish the above model as well as to shed light on the educational context factors in the Universities that could foster faculty members to make effective use of LMS (Granic \& Marangunic, 2019). Finally, the relationship among instructors' demographics and behavioral intention to use LMS was not tested in this study; therefore, future research could empirically test these relationships. 


\section{Conclusions}

Concerning the 1st research aim, the findings suggest that this TAM with five external factors can be implemented to identify specific constructs affecting faculty members' intention to use LMS; therefore, the findings support the applicability of TAM with faculty members data as well as the finding that the total explained variance of behavioral intention to use LMS is very high (73\%). With regard to the 2nd research aim, personal factors had a greater effect than environmental factors on the behavioral intention of faculty members to use LMS. From the personal factors, the perceived usefulness and perceived ease of use have a moderate total effect, and perceived self-efficacy has a small indirect effect on behavioral intention. From the environmental factors, the technological complexity, facilitating conditions, and social influence only have an indirect effect on behavioral intention. The study recommends training and technical support of faculty members. Moreover, stakeholders should be concerned about these factors to increase ease of use, awareness of new affordances to the educational community, accessibility, and general dissemination of LMS benefits in education.

This study contributes to the existing bibliography since there are not many studies that investigate the adoption of LMS by faculty members worldwide and mainly in Greece. Moreover, this study presents a clearer and broader image including various external factors that explain faculty members' behavioral intention to use LMS. The findings could shed light on the basic factors that affect faculty members to use e-learning systems in general in higher education. Finally, these findings can be the basis for future research and, in particular, in comparing findings before and during the COVID-19 pandemic (Şahin, et al., 2021) since faculty who use LMS at least once a week participated in this research. In this frame, it is of big importance that similar studies should be conducted.

Acknowledgements The authors would like to acknowledge the contribution of faculty members who participated in this survey as well as of Mr. F. Davis that allowed the use of TAM for this research. Moreover, we express our gratitude to Mr. Leonidas Sotiropoulos for editing the English version of this paper.

Authors' contribution All authors contributed to the study conception, design, and data collection. The analysis was performed by Konstantinos Lavidas. The first draft of the manuscript was written by Anthi Achriani and Konstantinos Lavidas and all authors commented and approved the final manuscript.

Funding Not applicable' for that section.

\section{Declarations}

Conflict of interest None. 


\section{Appendix}

\section{Questionnaire}

\section{Behavioral intention to use (BI)}

I intend to use the functions and content of LMS to assist in my academic activities. I intend to use the functions and content of LMS as often as possible.

I intend to use the functions and content of LMS in future.

\section{Attitude toward using (ATT)}

I like using the LMS.

I think it is worthwhile to use LMS.

In my opinion, it is very desirable to use LMS for academic and related purposes. I have a generally favorable attitude toward using LMS.

\section{Perceived ease of use (PEOU)}

My interaction with LMS would be clear and understandable.

It would be easy for me to become skillful at using LMS.

I would find it easy to get LMS to do what I want it to do.

I would find LMS easy to use.

\section{Perceived usefulness (PU)}

Using LMS in my job would increase my productivity.

I would find LMS useful in my job.

Using LMS would enhance my effectiveness on the job.

Using LMS would improve my job performance.

\section{Perceived self-efficacy (PSE)}

I could complete the job using the LMS if I had only the LMS manuals for reference. I could complete the job using the LMS if I could call someone for help if I got stuck.

\section{Subjective norms (SN)}

People who are important to me think that I should use the LMS. 
People whose opinions I value will encourage me to use LMS.

\section{Facilitating conditions (FC)}

Specialized instruction concerning the LMS is available to me.

A specific person (or group) is available for assistance with LMS difficulties. Guidance is available to me in the selection of LMS.

\section{Image (I)}

People in my organization who use the LMS have more prestige than those who do not.

People in my organization who use the LMS have a high profile.

\section{Technological complexity (TC)}

It takes too long to learn how to use an LMS to make it worth the effort.

Using an LMS takes too much time from my normal duties.

\section{References}

Ajzen, I., and Fishbein, M. (1980). Understanding attitudes and predicting social behavior. Englewood cliffs NY Prentice Hall. https: //doi.org/Z

Al-busaidi, K. A., and Al-shihi, H. (2010). Instructors' Acceptance of Learning Management Systems: A Theoretical Framework. Communications of the IBIMA, 2010. Retrieved from https://ibimapubli shing.com/articles/CIBIMA/2010/862128/862128.pdf.

Alharbi, S., \& Drew, S. (2014). Using the technology acceptance model in understanding academics' behavioural intention to use learning management systems. International Journal of Advanced Computer Science and Applications (IJACSA), 5(1), 143-155. https://doi.org/10.14569/IJACSA. 2014.050120

Al-Nuaimi, M. N., \& Al-Emran, M. (2021). Learning management systems and technology acceptance models: a systematic review. Education and Information Technologies. https://doi.org/10.1007/ s10639-021-10513-3

Altawalbeh, M. A., \& Alassaf, H. (2018). Antecedents and consequences of e-learning adoption in jordanian higher education institution. Advances in Social Sciences Research Journal, 5(5), 378-387. https://doi.org/10.14738/assrj.55.4586

Asiri, M. J. S., Mahmud, R., Bakar, K., \& Ayub, A. (2012). Factors influencing the use of learning management system in Saudi Arabian higher education: a theoretical framework. Higher Education Studies, 2(2), 125-137. https://doi.org/10.5539/hes.v2n2p125

Baleghi-Zadeh, S., Ayub, A. F. M., Mahmud, R., \& Daud, S. M. (2017). The influence of system interactivity and technical support on learning management system utilization. Knowledge Management \& E-Learning, 9(1), 50-68. https://doi.org/10.34105/j.kmel.2017.09.004

Chaw, L. Y., \& Tang, C. M. (2018). What makes learning management systems effective for learning? Journal of Educational Technology Systems, 47(2), 152-169. https://doi.org/10.1177/0047239518 795828

Cigdem, H., \& Topcu, A. (2015). Predictors of instructors' behavioral intention to use learning management system: a Turkish vocational college example. Computers in Human Behavior, 52, 22-28. https://doi.org/10.1016/j.chb.2015.05.049

Cohen, J. (1977). Statistical Power Analysis for the Behavioral Sciences (Revised). Academic Press. 
Compeau, D. R., and Higgins, C. A. (1995). Computer Self-Efficacy: Development of a Measure and Initial Test. MIS Quarterly, 19(2), 189-211. Retrieved from http://www.jstor.org/stable/249688.

Creswell, J. W. (2002). Educational Research: Planning, Conducting, and Evaluating Quantitative. Prentice-Hall.

Dahlstrom, E., Brooks, D., and Bischel, J. (2014) The Current Ecosystem of Learning Management Systems in Education: Student, Faculty, and IT Perspectives. Louisville, CO: ECAR

Davis, F. D. (1989). Perceived Usefulness, Perceived Ease of Use, and User Acceptance of Information Technology. Management Information System Research Center, 13(3), 319-340. Retrieved from http://www.jstor.org/stable/249008.

Eraslan Yalcin, M., \& Kutlu, B. (2019). Examination of students' acceptance of and intention to use learning management systems using extended TAM. British Journal of Educational Technology, 50(5), 2414-2432. https://doi.org/10.1111/bjet.12798

Escobar-Rodriguez, T., \& Monge-Lozano, P. (2012). The acceptance of Moodle technology by business administration students. Computers \& Education, 58(4), 1085-1093. https://doi.org/10.1016/j. compedu.2011.11.012

Fathema, N., Shannon, D., \& Ross, M. (2015). Expanding the technology acceptance model (TAM) to examine faculty use of learning management systems (LMSs) in higher education institutions. MERLOT Journal of Online Learning and Teaching, 11(2), 210-232. https://doi.org/10.12720/ joams.4.2.92-97

Fornell, C., \& Larcker, D. F. (1981). Evaluating structural equation models with unobservable variables and measurement error. Journal of Marketing Research, 18(1), 39-50.

Garone, A., Pynoo, B., Tondeur, J., Cocquyt, C., Vanslambrouck, S., Bruggeman, B., \& Struyven, K. (2019). Clustering university teaching staff through UTAUT: implications for the acceptance of a new learning management system. British Journal of Educational Technology, 50(5), 2466-2483. https://doi.org/10.1111/bjet.12867

Granic, A., \& Marangunic, N. (2019). Technology acceptance model in educational context: a systematic literature review. British Journal of Educational Technology., 50(5), 2572-2593.

Hair, J. F., Hult, G. T. M., Ringle, C. M., \& Sarstedt, M. (2017). A primer on partial least squares structural equation modeling (PLS-SEM) (2nd ed.). Sage.

Jaschik, S., and Lederman, D. (2014). The 2014 Inside Higher Ed Survey of faculty Attitudes on Technology: A Study by Gallup and Inside Higher Ed. Washigton, DC. Retrieved from: https://www.insid ehighered.com/news/survey/online-ed-skepticism-and-self-sufficiency-survey-faculty-views-techn ology.

Lavidas, K., Achriani, A., Athanassopoulos, S., Messinis, I., \& Kotsiantis, S. (2019). University students' intention to use search engines for research purposes: a structural equation modeling approach. $E d u$ cation and Information Technologies, 25, 2463-2479. https://doi.org/10.1007/s10639-019-10071-9

Lavidas, K., \& Gialamas, V. (2019). Adaption and psychometric properties of the short forms MarloweCrowne social desirability scale with a sample of Greek university students. European Journal of Education Studies, 6(8), 230-239. https://doi.org/10.5281/zenodo.3552531

Ling, L. W., Downe, A. G., Ahmad, W. F. W., \& Lai, T. T. (2011, September) Determinants of computer usage among educators: A comparison between the UTAUT and TAM models. In 2011 National Postgraduate Conference (pp. 1-6). IEEE Doi: https://doi.org/10.1109/NatPC.2011.6136322

Moodle (2019). https://Moodle.net/stats/ Accessed in 28 August 2019.

Panigrahi, R., Srivastava, P. R., \& Sharma, D. (2018). Online learning: adoption, continuance, and learning outcome-A review of literature. International Journal of Information Management, 43, 1-14.

Parissi, M., Komis, V., Lavidas, K., Dumouchel, G., \& Karsenti, T. (2019). A pre-post study to assess the impact of an information-problem solving intervention on university students' perceptions and selfefficacy towards search engines. International Journal of Technologies in Higher Education, 16(1), 68-87. https://doi.org/10.18162/ritpu-2019-v16n1-05

R Core Team (2018). R: A language and environment for statistical computing. R Foundation for Statistical Computing, Vienna, Austria. URL https://www.R-project.org/.

Rindfuss, R. R., Choe, M. K., Tsuya, N. O., Bumpass, L. L., \& Tamaki, E. (2015). Do low survey response rates bias results? Evidence from Japan. Demographic Research, 32, 797-828. https://doi. org/10.4054/DemRes.2015.32.26

Şahin, F., Doğan, E., İlic, U., \& Şahin, L. Y. (2021). Factors influencing instructors' intentions to use information technologies in higher education amid the pandemic. Education and Information Technologies. https://doi.org/10.1007/s10639-021-10497-0 
Sanchez, G. (2013). PLS Path Modeling with R. Berkeley: Trowchez Editions. Retrieved from http:// www.gastonsanchez.com/PLSPath Modeling with R.pdf.

Sanchez,G, Trinchera, L., and Russolillo, G. (2017). plspm: Tools for Partial Least Squares Path Modeling (PLS-PM). R package version 0.4.9. https://CRAN.R-project.org/package=plspm.

Teo, T. (2009). Modelling technology acceptance in education: a study of pre-service teachers. Computers and Education, 52(2), 302-312. https://doi.org/10.1016/j.compedu.2008.08.006

Teo, T. (2010). Examining the influence of subjective norm and facilitating conditions on the intention to use technology among pre-service teachers: a structural equation modeling of an extended technology acceptance model. Asia Pacific Education Review, 11(2), 253-262. https://doi.org/10.1007/ s12564-009-9066-4

Teo, T., Zhou, M., Fan, A. C. W., \& Huang, F. (2019). Factors that influence university students' intention to use Moodle: a study in Macau. Educational Technology Research and Development, 67(3), 749-766. https://doi.org/10.1007/s11423-019-09650-х

Thompson, R. L., Higgins, C. A., \& Howell, J. M. (1991). Personal computing: toward a conceptual model of utilization. MIS Quarterly, 15(1), 125-143.

Venkatesh, V., \& Davis, F. D. (2000). A theoretical extension of the technology acceptance model: four longitudinal field studies. Management Science, 46(2), 186-204.

Venkatesh, V., Morris, M. G., Davis, G. B., \& Davis, F. D. (2003). User acceptance of information technology: toward a unified view. MIS Quarterly, 27(3), 425-478. https://doi.org/10.1017/CBO97 81107415324.004

Waheed, M., Kaur, K., Ain, N. U., \& Hussain, N. (2016). Perceived learning outcomes from moodle: an empirical study of intrinsic and extrinsic motivating factors. Information Development, 32(4), 1001-1013. https://doi.org/10.1177/0266666915581719

Wang, W., \& Wang, C. (2009). Computers and education an empirical study of instructor adoption of web-based learning systems. Computers and Education, 53(3), 761-774. https://doi.org/10.1016/j. compedu.2009.02.021

Wichadee, S. (2015). Factors related to faculty members' attitude and adoption of a learning management system. Turkish Online Journal of Educational Technology, 14(4), 53-61.

Zheng, Y., Wang, J., Doll, W., Deng, X., \& Williams, M. (2018). The impact of organisational support, technical support, and self-efficacy on faculty perceived benefits of using learning management system. Behaviour \& Information Technology, 37(4), 311-319. https://doi.org/10.1080/0144929X. 2018.1436590

Ziraba, A., Akwene, G. C., \& Lwanga, S. C. (2020). The adoption and use of moodle learning management system in higher institutions of learning: a systematic literature review. American Journal of Online and Distance Learning, 2, 1-21.

Publisher's Note Springer Nature remains neutral with regard to jurisdictional claims in published maps and institutional affiliations.

Konstantinos Lavidas is a teaching staff at Hellenic Open University and Research and Laboratory Teaching Staff at the University of Patras (Department of Educational Sciences and Early Childhood Education). His research interests concern ICT in Education, STEM, and Educational Research Methods. (ORCID: 0000-0003-2225-1137) lavidas@ upatras.gr

Vassilis Komis is a professor at the University of Patras (Department of Educational Sciences and Early Childhood Education) in the field of Didactics of Informatics and ICT applications in Education. His research interests concern Digital Technologies in Education, Technology Enhanced Learning, Learning Design, Teachers Training, Computational Thinking in Education, and Computer Science Education. (ORCID: 0000-0001-6909-2765), komis@ upatras.gr

Anthi Achriani is a preschool educator with a M.Sc: Natural Sciences Didactics: Curriculum, Evaluation and ICT in Education from University of Patras. Her research interests concern ICT in Education. anthi.achriani@gmail.com 